\title{
樹木の降雨遮断モラ゙ルとパうメータ推定法に 関す方奏験的研究
}

A Experimental Study on Rainfall Interception Model and Parameter Estimation Method

$$
\begin{array}{lll}
\text { 徳島大学工学部 } & \text { 端 野 道 夫 M.Hashino } \\
\text { 香川大学農学部 } & 大 & \text { 槻 恭 }- \text { K.0tsuki }
\end{array}
$$

\section{1・はしがき}

樹冠による降雨遮断作用は森林流域からの水分損失の内で大きな比重を占めており、流域の水収支の解 明には降雨遮断の量的評価が不可欠である。しかし、降雨遮断に関する旧来よりの多くの観測研究にもか かわらず、樹冠の濡れ具合の表現の困難さと樹冠付近の複雑な微気象的条件等により、解明されねばなら ない多くの問題が残されている。

本研究では、樹幹および枝葉を含む樹木全体に付着した雨水量を “樹木”タンクモデルで表現し、降雨 遮断に関連するパラメータを、主としてて樹幹流下量の時間変化データと雨滴落下開始、終了の時間情報よ り推定する方法を検討する。すなわち、林内雨の量的データがなくとも降雨遮断パラメー夕を評価できる 方法を娭討する。パラメー夕推定法の検討用データとして、幼令単木を用いた降雨遮断実験デー夕を用い ることにし、降雨終了後の推定付着水量の妥当性を種々の角度より検討する。

2. 降雨遮断モデルとパラメータ推定法

\section{1 Łデルの基本式と特徵}

一般に、森林の樹冠（枝, 幹を含志）を一つのタンクと見なすと、この“樹木”タンクについての水収 支式は次式で与えられる。

$$
\mathrm{d} S / \mathrm{dt}=\mathrm{r}-\mathrm{E}-\mathrm{d}-\mathrm{q}
$$

己こR、S：樹冠付着水分高、すなわち雨水貯留高, $\mathrm{r}$ : 降雨強度, $\mathrm{E}$ ：樹冠面加らの付着水の蒸発強度,

$\mathrm{d} ：$ 樹冠からの（付着水の）雨滴落下強度, $\mathrm{q}$ : 樹冠付着水の樹幹流下強度である。

雨滴落下強度 $\mathrm{d}$ 、樹幹流下強度 $\mathrm{q}$ については、次式の上うに、眝留高 $\mathrm{S}$ の関数とし、降雨中 $(\mathrm{r}>0)$ と降雨停止後（r=0）では、一般にパラメータは異なるものとする（図 1参照）。すなおち、

$$
\begin{aligned}
& d=D /\{(1-p) A\}=\left\{\begin{array}{cc}
0 & \left(0 \leqq S \leqq h_{d}, r>0 ; 0 \leqq S \leqq h_{d} z, r=0\right) \\
\lambda_{d}\left(S-h_{d}\right) & \left(h_{d}<S, r>0\right) \\
\lambda_{d z}\left(S-h_{d}\right) & \left(h_{d}<S, r=0\right)
\end{array}\right. \\
& q=a /\{(1-p) A\}=\left\{\begin{array}{cc}
0 & \left(0 \leqq S \leqq h_{s}, r>0 ; 0 \leqq S \leqq h_{s 2}, r=0\right) \\
\lambda_{s}\left(S-h_{s}\right) & \left(h_{s}<S, r>0\right) \\
\lambda_{s 2}\left(S-h_{s 2}\right) & \left(h_{s 2}<S, r=0\right)
\end{array}\right.
\end{aligned}
$$

ここに、A：(樹木の枝葉の及ぶ）基準とする面積， $\mathrm{p}$ : 基準面積 Aに降った降雨分の内、枝葉にまった

くふれずに樹間を通過する、直達降雨の割合， $Q$ ：樹幹流下量， D：枝葉からの雨滴落下量である。

このモデルの特徵として、次の二点があげられる。

(1)樹冠からの付着水の蒸発強度 Eは、気温, 風速, 湿度, 日射量, 日照時間等の気象条件により規定さ れるものであり、貯留高 Sの関数とはしない。

(2)降雨中と降雨終了後では、樹冠面への雨滴衝撃効果の有無により、P以外のパラメー夕の值は異なる。 すなわち、降雨中の $\lambda_{d}, \lambda_{s}, h_{d}, h_{s} は$ 降雨終了後 $\lambda_{d 2}, \lambda_{s a}, h_{d}, h_{s}$ に変化するとする。したが って、降雨遮断に最も関連の深いパラメー夕は で志机ば、雨滴落下することなく、これだけの量がすべて点発することになる。 


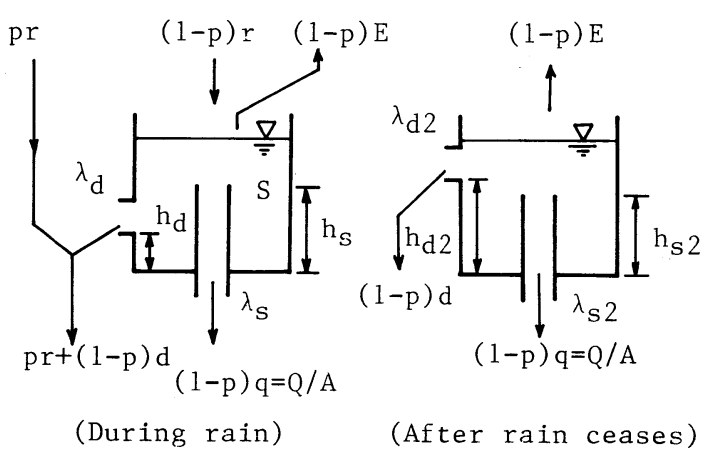

図 1 本降雨遮断モデル

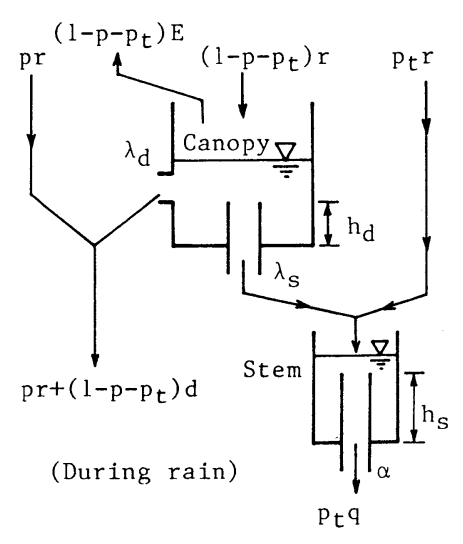

図２Ｒutter モデルの改良型

本モデルは武田 ' が提案したものを前述の 2 点で改良したものに相当する。外国では Rutter モデル2 が知られているが、これは樹木の枝葉部と樹幹部を独立とした、いわ浓る“並列”タンクモデルである。 雨水の移動形態から見れば、枝葉部と樹幹部につながりを付けたモデルの方（図一2 参照）が自然でる。 しかし、この場合、モデルパラメー夕は本モデルより増えるため、パラメータ推定に難がある。

\section{2 一定降雨強度のときの樹幹流下量の時間変化}

一定強度 rの降雨が始まり、林内雨滴落下および樹幹流下が定常になるまで十分長く降り続いた場合を 考える。林内雨滴落下、樹幹流下の各々の開始時刻を $t_{11}, t_{s 1}$ とし、雨滴落下、樹幹流下の各々の終了時 刻を $t_{d 2}, t_{s}$ とすれば、 $t_{d} 1<t_{s 1}, t_{d 2}<t_{s}$ である場合が多いようであるので、以下では、この場合につ いてのみ記すことにする。

式(1)，(2)を式（1）に代入し、(1) $0<t \leqq t_{d}$, (2) $t_{d} 1<t \leqq t_{s 1}$, (3) $t_{s 1}<t \leqq t_{r}$ （tr: 降 雨終了時刻), (4) $t_{r}<t \leqq t_{d}$, (5) $t_{d} 2<t \leqq t_{s}$, (6) $t_{s} 2<t$ の各時間帯について式 (1) 眝 留高 $S$ にいて積分すれば、容易に以下の結果を得る。

(1)のとき $h_{d}=(r-E) t_{d}$

(2)のとき $\quad h_{s}-h_{d}=(r-E)\left[1-\exp \left\{-\lambda_{d}\left(t_{s 1}-t_{d 1}\right)\right\}\right] / \lambda_{d}$

(3)のとき $R_{s} \equiv(1-p) \int_{t_{s 1}}^{t_{r}} q d t=\frac{0^{*}}{A}\left[\left(t_{r}-t_{s 1}\right)-\frac{1}{\lambda}\left[1-\exp \left\{-\lambda\left(t_{r}-t_{s 1}\right)\right\}\right]\right]$

$$
\frac{Q^{*}}{A}=\frac{(1-p) \lambda_{s}}{\lambda}\left\{r-E-\lambda_{d}\left(h_{s}-h_{d}\right)\right\} \quad\left(\lambda \equiv \lambda_{s}+\lambda_{d}\right)
$$

ここに、Rs : 累加樹幹流下量 $(\mathrm{mm}), Q^{*} / A$ : 定常状態における観測樹幹流下強度 $0 / A(\mathrm{~mm} / \mathrm{h}) て ゙ 、 r$ とは式（7）の関係がある。また、定常状態（添字*を付す）では次の関係式が成り立つ。

$$
\begin{gathered}
S^{*}=\left(r-E+\lambda_{d} h_{d}+\lambda_{s} h_{s}\right) / \lambda=\left(r-E+\lambda_{d} 2 h_{d} 2+\lambda_{s 2} h_{s 2}\right) / \lambda_{2} \\
\left(\lambda_{2} \equiv \lambda_{s 2}+\lambda_{d 2}\right) \\
0^{*} / A /(1-p)=q^{*}=\lambda_{s}\left(S^{*}-h_{s}\right)=\lambda_{s 2}\left(S^{*}-h_{s 2}\right) \\
r-E-q^{*}=d^{*}=\lambda_{d}\left(S^{*}-h_{d}\right)=\lambda_{d 2}\left(S^{*}-h_{d 2}\right)
\end{gathered}
$$

(4)のとき $Q(t) / A=Q^{*} / A-(1-p) r \frac{\lambda_{s 2}}{\lambda_{2}}\left[1-\exp \left\{-\lambda_{2}\left(t-t_{r}\right)\right\}\right] \quad\left(t_{r} \leqq t \leqq t_{d} 2\right)$ 


$$
E+\lambda_{s 2}\left(h_{d 2}-h_{s 2}\right)=r \exp \left\{-\lambda_{2}\left(t_{d 2}-t_{r}\right)\right\}
$$

(5)のとき $Q(t) / A /(1-p)=-E+\left\{\lambda_{s 2}\left(h_{d} z-h_{s} 2\right)+E\right\} \exp \left\{-\lambda_{s} 2\left(t-t_{d} 2\right)\right\} \quad\left(t_{d} 2 \leqq t \leqq t_{s}\right)(13)$

$$
E+\lambda_{s 2}\left(h_{d 2}-h_{s 2}\right)=E \exp \left\{\lambda_{s 2}\left(t_{s 2}-t_{d 2}\right)\right\}
$$

(6)のとき $h_{s 2}=E\left(T-t_{s 2}\right)$

( $\mathrm{T}$ : 樹冠乾燥時刻)

厳密には、蒸発強度 Eは各時間帯の気象条件の変化により異なると考元られるが、解析では、(1) (3)の 降雨中 $\left(0 \leqq t \leqq t_{r}\right)$ ，(4)〜(5)の降雨終了後樹幹流下終了まで（ $\left.t r \leqq t \leqq t t_{52}\right)$ ，(6)樹冠付着水が無くなるま

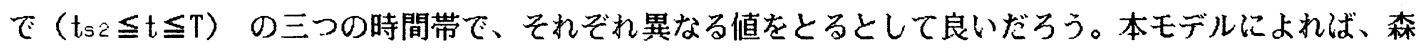
林の降雨遮断特性を最む明膫に表すのがパラメータ $h_{52}$ （：樹幹流下終了時の樹冠貯留高）であり、この 值が大である程、式(15)のように、降雨終了後の樹冠付着水の蒸発量が大きくなる。

2. 3 パラxー夕推定法

平均降雨強度 $r$, 雨滴落下開始時刻 $t_{d 1}$, 同終了時刻 $t_{d 2}$, 樹幹流下開始時刻 $t_{s 1}$, 同終了時刻 $t_{s}<お ~$ よび樹幹流下量 $Q(t)$ が観測されている場合について、パラメータの推定順に、述べる。

i) $\lambda_{2} \equiv \lambda_{\mathrm{s} 2}+\lambda_{\mathrm{d} 2}$ の推定 式(11)を $\mathrm{t}_{\mathrm{r}}<\mathrm{t}<\mathrm{t}_{\mathrm{d} 2}$ の時刻 $t=\mathrm{t}_{1}, \mathrm{t}_{2}, \mathrm{t}_{3}$ （ただし、 $\mathrm{t}_{2}-\mathrm{t}_{1}$ $=t_{3}-t_{2}$ とする) について適用し、三つの式を得る。 $t=t_{1}$, $t_{2}$ についての二つの式の両辺の差を 取ることにより次式を得る。

$\frac{\left\{Q\left(t_{1}\right)-Q\left(t_{2}\right)\right\} / A}{(1-p)}=\frac{\lambda_{s 2} r}{\lambda_{2}} \exp \left\{-\lambda_{2}\left(t_{1}-t_{r}\right)\right\} \quad\left[1-\exp \left\{-\lambda_{2}\left(t_{2}-t_{1}\right)\right\}\right]$

同様にして、式(16)の $t_{1}, t_{2}$ をそれぞれ $t_{2}, t_{3}$ に変更した式を得る。この二つの式の両边の積より次 式が得られる。

$$
\lambda_{2} \equiv \lambda_{\mathrm{s} 2}+\lambda_{\mathrm{d} 2}=\frac{-1}{\left(t_{2}-t_{1}\right)} \ln \left[\left\{0\left(t_{2}\right)-Q\left(t_{3}\right)\right\} /\left\{Q\left(t_{1}\right)-Q\left(t_{2}\right)\right\}\right]
$$

ii $\lambda_{s 2}, \lambda_{d 2} ，(1-p)$ の推定 式 (9),(10),(12)を用いて、(hd2 - $\left.h_{s 2}\right)$ を消去すると次式が得 られる。

$$
\left(1+k_{2}\right) Q^{*} / A /(1-p)=(r-E) k_{2}-E+r \exp \left\{-\lambda_{2}\left(t_{d} 2-t_{r}\right)\right\}
$$

ここに、 $k_{2} \equiv \lambda_{s 2} / \lambda_{d 2}$ である。式 (16),(18)を用いて、(1-p)を消去すると次式が得られる。

$$
\begin{aligned}
k_{2} \equiv \lambda_{s 2} / \lambda_{\mathrm{d} 2}= & {\left[r \exp \left\{-\lambda_{2}\left(\mathrm{t}_{2}-\mathrm{tr}_{\mathrm{r}}\right)\right\}-\mathrm{E}\right] /\left[\mathrm { r } \left[\exp \left\{-\lambda_{2}\left(\mathrm{t}_{1}-\mathrm{tr}_{\mathrm{r}}\right)\right\}\right.\right.} \\
& \left.\left.-\exp \left\{-\lambda_{2}\left(\mathrm{t}_{2}-\mathrm{tr}_{\mathrm{r}}\right)\right\}\right] \mathrm{Q}^{*} / \mathrm{A}-(\mathrm{r}-\mathrm{E})\left\{0\left(\mathrm{t}_{1}\right)-Q\left(\mathrm{t}_{2}\right)\right\} / \mathrm{A}\right]
\end{aligned}
$$

前述のように、 $t_{r}<t<t_{s} \varepsilon$ の時間帯にお和る平均蒸発強度を $E=E_{2}$ とすれば、式(12),(14)より

$$
\mathrm{E}=\mathrm{E}_{2}=r \exp \left\{-\lambda_{\mathrm{s} 2}\left(\mathrm{t}_{\mathrm{s} 2}-\mathrm{t}_{\mathrm{r}}\right)-\lambda_{\mathrm{d} 2}\left(\mathrm{t}_{\mathrm{d} 2}-\mathrm{t}_{\mathrm{r}}\right)\right\}
$$

となる。したがって、式(17)で与えられる $\lambda_{2}$ と $E=E_{2}=0$ を初期值として、式(19),(18),(20)およ び式(11)て $\mathrm{t}=\mathrm{t}_{3}$ とした式の順に繰り返し、収束したときの值で $\lambda_{\mathrm{s} 2}, \lambda_{\mathrm{d} 2},(1-p)$, および $\mathrm{E} z$ を確 定する。

iii) $\lambda_{s}, \lambda_{d}$ の推定 式(6) で、観測データより、時間 $\left(t_{r}-t_{s 1}\right)$ までの累加樹幹流下量 $R_{s}=$ $\sum Q / A(\mathrm{~mm})$ と定常状態での樹幹流下強度 $Q^{*} / A(\mathrm{~mm} / \mathrm{h})$ が与えられるゅえ、式(6) は $\lambda \equiv \lambda_{s}+\lambda_{\mathrm{d}}$ に 関する非線形方程式となる。これを Newton 法で解く。式(5)を式(7)に代入すると、

$$
(1+k) 0^{*} / A=(1-p)(r-E) k \exp \left[-\lambda\left(t_{s 1}-t_{d 1}\right) /(1+k)\right]
$$

となる。降雨中の蒸発強度 $E_{1}$ を $r>E_{1} \fallingdotseq 0$ とすれば式(21)は $k \equiv \lambda_{s} / \lambda_{d}$ に関する非線形方程式と

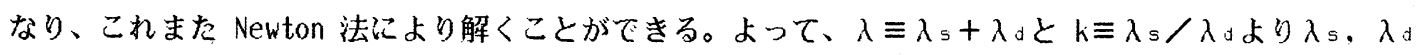


が求められる。

iv) $h_{s}$, hd, $h_{s} 2$, hdz の推定 式(4),(5)において、E = $E_{1} \doteqdot 0$ とすれば、直ちに、 $h_{d}, h_{s}$ が求まる。これを式(8) に代人すれば、定常時の貯留高 $S^{*}$ が求まり、式(9),(10)より、最後にhd2, $h_{s} 2$ が求まる。

以上のパラメータ推定法は降雨強度を一定とした場合であるが、実森林流域のように、降雨強度が変化 する場合についても原理的にほぼ同样な方法により、パラメータを推定することができるが、これについ ては別の機会に譲ることにする。

\section{4 水収支による蒸発強度の推定法}

樹冠付着水の蒸発強度 Eは、前述のように、大きく分けて(1)降雨中, (2)降雨終了後より樹幹流下終了ま で（ $t_{d 2}<t_{s} 2$ のとき）, (3)樹幹流下終了後より樹幹付着水が無くなるまでの三つの時間帯で異なると考 えられる。それぞれの蒸発強度 $\mathrm{E}$ を $E_{1}, E_{2}, E_{3}$ とすれば、E2 については式(20)のように、雨滴落下、 樹幹流下の各終了時刻 $t_{d 2}, t_{s 2}$ と関係があることがわかる。

$E_{3}$ の推定については、式(15)より明らかなように、樹幹流下終了時より樹冠付着水が無くなるまでの 時刻 Tを何等かの方法により観測する必要がある。

降雨中の蒸発強度 E 1 については、以下のように、樹幹流下量 $0(t)$ 観測デー夕はもちろんのこと、林 内雨量 $(p \cdot r(t)+D(t) / A)$ についての観測デー夕が不可欠となる。降り始めより、十分時間が経過した ときまでの累加樹幹流下量、累加林内雨量をそれぞれ、Rs, Rt とし、降雨量 $R(=r \cdot t)$ と $\left(R_{s}+R_{t}\right)$ との差を降雨遮断量 $R_{i}$ とする。 $r=$ 定のとき、Rs は式(6)で与えられる。Rtに関する式も式（6)を得 た方法と同様な方法により容易に得られる。したがって、Ri と $R$ に関する次式を得る。

$$
R_{i}(t)=R(t)-R_{s}(t)-R_{t}(t)=(1-p)(E / r) R(t)-b_{i}
$$

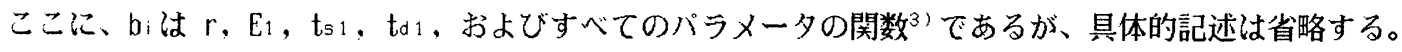
式(22)降雨開始時間より十分時間が経過した時刻 $t=t_{4}, t_{5},\left(t_{4}<t_{5}\right)$ について適用し、これら 二式の差より次式を得る。

$$
E_{1}=\frac{r}{(1-p)} \cdot \frac{\left\{R_{i}\left(t_{5}\right)-R_{i}\left(t_{4}\right)\right\}}{\left\{R\left(t_{5}\right)-R\left(t_{4}\right)\right\}}
$$

なお、式(22)のような、降雨遮断量 Ri と降雨量 Rの一次関係は実地の観測からよく知られているとこ ろであるが、その係数 $(1-p) E_{1} / r$ と定数 $b_{i}$ の物理的裏付けが本モデルにより明確なものとなった といえる。

3. 単木降雨遮断実験データの場合のパラメータ推定と検討

\section{1 降雨遮断実験の概要}

図 3に示すように、高さ約 $1.8 \mathrm{~m}$ のモミ，サンゴジュ(樹 令 10,8 年) の単木に一定強度の人工降雨（室内）を降らせ、 樹間通過量（枝葉からの雨滴落下量と直達降雨量の和）と樹 幹流下量の時間変化を計測する。樹間通過量は2 24.5 の傾き を持つ $1.2 \times 1.2 \mathrm{~m}$ の集水板（タキロンPPプレート）で受什、 これを幅 $2 \mathrm{~mm}$ の矩形堰に導く。樹幹流下量は市販の $500 \mathrm{cc} x$ スシリンダーに導く。降雨強度は一定とし、降雨開始より樹 幹流下量及び樹間通過量が定常になるるまで十分な時間を置き、 降雨在停止する。降雨終了後、樹幹流下量崩よじ樹間通過量 が無くなるまで両者を計測する。その他、降雨開始後、枝葉

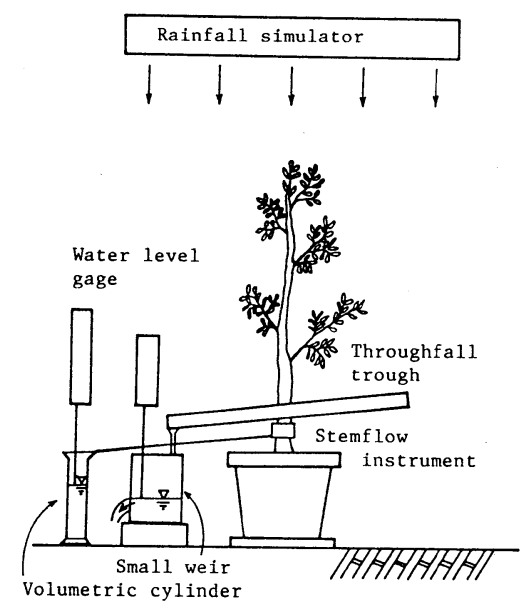

図 3 実験装置 
からの雨滴落下開始時刻 $t_{d} 1$ と、降雨終了後、雨滴落下終了時刻 $t_{d z}$ を目視により記録する。このときの 降雨強度は定常時の樹幹流下強度と樹間通過強度の和で与える。したがって、本実験にお沛る降雨中の蒸 発強度 $E_{1}$ は $E_{1}=0$ と見なすことになる。

樹間通過強度の時間変化は集水板の影響を受汁、その増加部とてい減部においてかなり大きな時間遅れ が見られる。したがって、その定常時の值のみを降雨強度算定に用いることにする。

\section{2 推定されたパラメータと適合度}

2.3で述べた推定法により、推定されたパラメー夕值を表 1に示す。また、樹幹流下量の時間変化の 実測值に対する適合度の一例を図 4に示す。図 4では樹間通過量デー夕は単なる参考データとし、パラメ 一夕推定には用いていない。この図より明らかなように、降雨中の樹幹流下量増加部および降雨停止後の 樹幹流下量低減部とも実測值に対する適合度は良好であり、本モデルは降雨の樹幹流下および枝葉からの 雨滴落下特性をほぼ再現することができる。
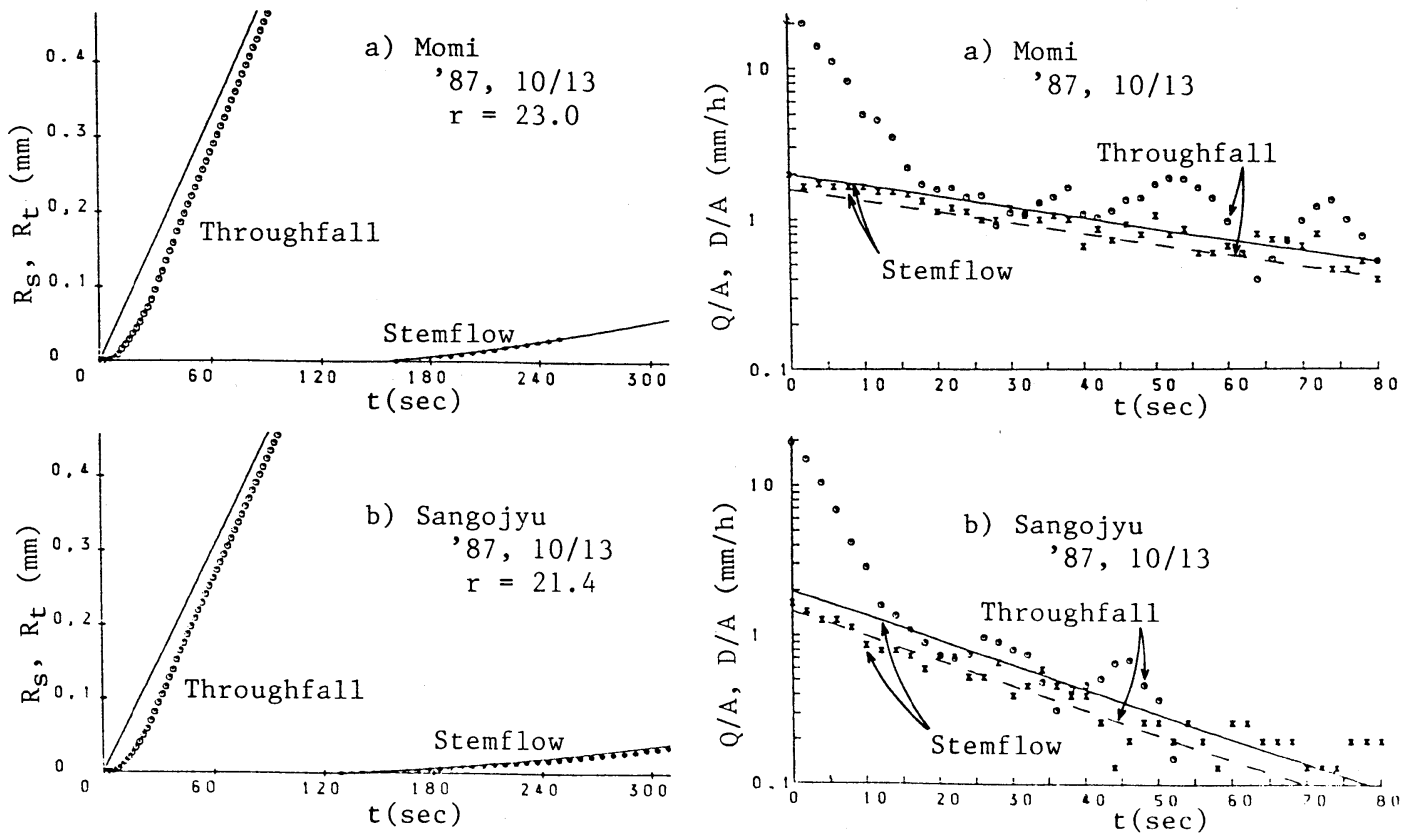

図 $\quad 4$ 害測值记対する計算值の適合度

表 1 推定されたパラメー夕の値

\begin{tabular}{|c|c|c|ccccccccc|}
\hline Species & Date & $\begin{array}{c}\mathrm{r} \\
(\mathrm{mm} / \mathrm{h})\end{array}$ & $(1-\mathrm{p})$ & $\begin{array}{c}\lambda_{\mathrm{d}} \\
(\mathrm{l} / \mathrm{h})\end{array}$ & $\begin{array}{c}\lambda_{\mathrm{s}} \\
(1 / \mathrm{h})\end{array}$ & $\begin{array}{c}\lambda_{\mathrm{d} 2} \\
(1 / \mathrm{h})\end{array}$ & $\begin{array}{c}\lambda_{\mathrm{s} 2} \\
(1 / \mathrm{h})\end{array}$ & $\begin{array}{c}\mathrm{h}_{\mathrm{d}} \\
(\mathrm{mm})\end{array}$ & $\begin{array}{c}\mathrm{h}_{\mathrm{s}} \\
(\mathrm{mm})\end{array}$ & $\begin{array}{c}\mathrm{h}_{\mathrm{d} 2} \\
(\mathrm{~mm})\end{array}$ & $\begin{array}{c}\mathrm{h}_{\mathrm{s} 2} \\
(\mathrm{~mm})\end{array}$ \\
\hline Abies & $, 87,8 / 11$ & 22.4 & 0.154 & 10 & 34 & 30 & 60 & 0.28 & 0.89 & 1.01 & 1.01 \\
firma & $, 87,9 / 21$ & 19.7 & 0.160 & 11 & 18 & 30 & 33 & 0.14 & 0.67 & 0.82 & 0.82 \\
(Momi) & $, 87,10 / 13$ & 23.0 & 0.154 & 17 & 43 & 17 & 43 & 0.37 & 0.77 & 0.65 & 0.65 \\
& $, 87,11 / 5$ & 35.3 & 0.212 & 22 & 29 & 47 & 41 & 0.11 & 0.64 & 0.73 & 0.73 \\
\hline Viburnum & $, 87,8 / 11$ & 22.9 & 0.126 & 8 & 13 & 46 & 100 & 0.08 & 0.47 & 1.21 & 1.21 \\
awabuki & $, 87,9 / 21$ & 20.1 & 0.215 & 13 & 3 & 69 & 30 & 0.20 & 0.38 & 1.25 & 1.25 \\
(Sangojyu) & $, 87,10 / 13$ & 21.4 & 0.160 & 9 & 13 & 58 & 79 & 0.08 & 0.55 & 1.16 & 1.16 \\
& $, 87,11 / 5$ & 36.8 & 0.162 & 20 & 13 & 62 & 73 & 0.10 & 0.56 & 1.15 & 1.15 \\
\hline
\end{tabular}


表 1によれば、パラメータ値は、同一単木でむ、実験日の気温、実験日の単木設置位置の微妙な違い、 降雨強度の相違等により、入dと $\lambda_{\mathrm{s}}, \lambda_{\mathrm{d} 2}$ と $\lambda_{\mathrm{s} 2}$ の大小関係がそれぞれ変わり、数值は不安定であるが、

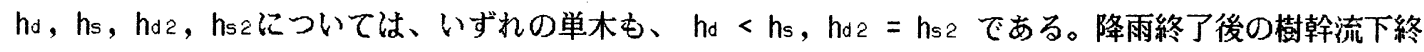
了時における樹冠付着高 $h_{s}$ 林表 1 によれば、モミで $0.65 \sim 1.01 \mathrm{~mm}$,サンゴジュで $1.15 \sim 1.25 \mathrm{~mm}$ であ る。この量は単層の葉面の付着水高ではなく、何層にもなっている莱面の付着水高を合計したものにほぼ 等しいと解釈され、この值を葉面積指数 If (無次元) で除せば、（単層）葉面一枚当りの付着水高とな ろう。もちろん、枝、幹の付着水も、この值に含まれている。

3.3 推定付着水高 $h_{s 2}$ の信頼性の検討

表 2 樹冠付着水推定值の比較

降雨終了後の樹冠付着水高 $h_{5}$ 2 は降 雨遮断量と蒸発量に最む関与するパラ メータであるので、別の方法による推 定值と比較し、その数值の信頼性を検 討する。実験に使用した単木の全付着

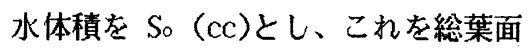
積で除した、（単層）葉面付着水高在 h。とする。これら二者を、(1)本モデ ルによる方法、(2)既知量の散水を単木

\begin{tabular}{|c|c|c|c|c|}
\hline \multirow{2}{*}{ Species } & \multicolumn{2}{|c|}{$\begin{array}{c}\text { Abies firma } \\
\left(\mathrm{p}=0.830, \mathrm{I}_{\mathrm{f}}=7\right)\end{array}$} & \multicolumn{2}{c|}{$\begin{array}{c}\text { Vihurnum awabuki } \\
\left(\mathrm{p}=0.834, \mathrm{I}_{\mathrm{f}}=6\right)\end{array}$} \\
\cline { 2 - 5 } & $\mathrm{S}_{\mathrm{o}}(\mathrm{cc})$ & $\mathrm{h}_{\mathrm{o}}(\mathrm{mm})$ & $\mathrm{S}_{\mathrm{o}}(\mathrm{cc})$ & $\mathrm{h}_{\mathrm{o}}(\mathrm{mm})$ \\
\hline Method 1 & $131 \sim 204$ & $0.08 \sim 0.13$ & $200 \sim 352$ & $0.15 \sim 0.27$ \\
\hline Method 2 & $167 \sim 283$ & $0.11 \sim 0.18$ & $145 \sim 238$ & $0.11 \sim 0.18$ \\
\hline Method 3 & 234 & 0.15 & 152 & 0.14 \\
\hline
\end{tabular}

に与え、流下、落下水量との差を付着水量 S。とする方法、(3)単木の一枝部分または数枚の葉を切り取り、 これの付着水量をそれぞれの葉面積で除して hoとし、これに葉面積指数 If を乗じて So を求める方法、 で求め比較すれば表 2のようになる。(1)の方法は $S_{o}=(1-p) \cdot A \cdot h_{s} 2, h_{0}=h_{s} / l_{i}$ より求めた。(2)のための 散水は園芸用如露で行い、本降雨発生装置の雨滴ノズル間隔とはかなり異なる。(3の方法では、h。の代 表性に若干疑問がある。また、葉面積指数 If の算定值には枝、幹を含んでいない。サンゴジュでは季節 変化に伴う、落葉がある。一方、8月11日の室内実験では、純放射量、葉面温度、菄面水晋気圧を計測し、 これをPenman 式に用い、モミ、サンゴジュの葉面蒸発強度 (降雨終了後約20分後) を算定するとそれぞ れ、 $0.069,0.044 \mathrm{~mm} / \mathrm{h}$ であり、さらに葉面乾燥時間約 3 時間を乗じると、h。 $\fallingdotseq 0.21,0.13$ となり、 表 2の数值とほぼオーダーが一致する。以上のようなことを配慮すれば、本タンクモデルの推定されたパ ラメータ hs2の信頼性はかなり高いといえよう。

\section{4.あとがき}

森林の降雨遮断機構を降雨中と降雨停止後でパラメータが変化するとした樹木タンクモデルで表現し、 主として樹幹流下量の時間変化データと雨滴落下開始、終了の時間情報を用いてモデルパラメータを推定 する方法を提案した。さらに、樹冠葉面付着水の蒸発強度と本モデルのパラメー夕との水収支的関係を降 雨中、降雨終了より樹幹流下終了まで、樹幹流下終了より樹冠付着水が無くなるまでの三つの時間帯に分 けて示し、蒸発強度を（本モデルを用いた）水収支により逆推定する方法を示した。さらに、単木降雨遮 断実験データを用いた樹木タンクモデルのパラメータ推定值、とくに、降雨終了後の推定付着水量の信頼 性を種々の角度より検討し、パラメータ推定法の妥当性を確認した。

\section{参考文献}

1)武田京一：林地雨量について, 気象集誌, Vol.9, No.6, pp.19〜32, 1951.

2)Rutter,A.J.et al.: A predictive model of rainfall interception in forests, Agric. Meteorol., Vol.9, pp.367 384, 1971.

3)端野・井内：樹木の降雨遮断モデルとパラメー夕推定に関する実験的研究, 土木学会年講, II-30,1987. 